\title{
Effects of Low-dose Propofol or Ketamine on Coughing at Emergence from Anesthesia in Children Undergoing Tonsillectomy
}

\author{
Mohammad Ali Sahmeddini ${ }^{1}$, Ashkan Panah ${ }^{1}$, Alireza Ghanbari ${ }^{1}$ \\ 1. Anesthesiology, Shiraz Anesthesiology and Critical Care Research Center, Shiraz University of Medical Sciences, \\ Shiraz, IRN
}

Corresponding author: Mohammad Ali Sahmeddini, sahmeddini@sums.ac.ir

\section{Abstract \\ Introduction}

Coughing is commonly observed during emergence from general anesthesia. In children, smooth emergence from anesthesia, especially after tonsillectomy, is crucial. In this study, we compared the effect of low-dose ketamine or propofol on emergence coughing in children undergoing tonsillectomy.

\section{Methods}

In this randomized clinical trial, 90 children undergoing tonsillectomy were randomly allocated into two groups: children in group A received $0.5-\mathrm{mg} / \mathrm{kg}$ propofol and children in group B received $0.5-\mathrm{mg} / \mathrm{kg}$ ketamine, at the end of anesthesia. The incidence and severity of cough, postoperative sedation, nausea, and vomiting, and pain score were recorded and compared.

\section{Results}

The incidence of no cough at emergence from anesthesia was $82.2 \%$ in the propofol group and $15.5 \%$ in the ketamine group $(\mathrm{P}=0.00)$. Children in the ketamine group exhibited postoperative pain but were more sedated compared with those in the propofol group $(P>0.05)$. The incidence of postoperative nausea and vomiting was lower in the propofol group $(\mathrm{P}<0.05)$.

\section{Conclusions}

At the end of general anesthesia with isoflurane in children undergoing tonsillectomy, $0.5-\mathrm{mg} / \mathrm{kg}$ propofol is more effective than $0.5-\mathrm{mg} / \mathrm{kg}$ ketamine in reducing cough response upon emergence from anesthesia, with a lower incidence of nausea and vomiting, as well as lower sedation in children.

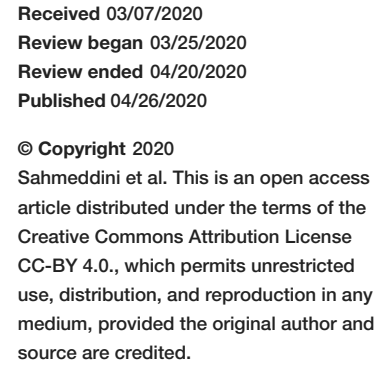

Categories: Anesthesiology, Otolaryngology

Keywords: tonsillectomy, ketamine, propofol, cough, anesthesia recovery period, children

\section{Introduction}

In children, smooth emergence from anesthesia, especially after tonsillectomy, is crucial [1]. At the end of surgery, an anesthesiologist usually decreases the depth of anesthesia to wake the child, but the endotracheal tube (ETT) can act as a foreign body and cause both cough and straining during emergence [2,3]. However, coughing and straining during emergence following tonsillectomy may cause post-tonsillectomy bleeding and laryngospasm, and increase pain and agitation [4].

Several studies have reported various methods and drugs to reduce the incidence of coughing and straining during emergence from anesthesia [5,6]. These include extubation at the deep plane of anesthesia, use of reinforced laryngeal mask instead of an ETT, and drugs such as intravenous or intratracheal tube lidocaine, intravenous magnesium sulfate, ketamine, and opioids [7-11]. Recent studies have highlighted the possible role of low-dose propofol as a suppressant of airway reflexes in noninvasive operations [12].

However, no studies have compared the effect of propofol with ketamine in reducing coughing and straining after tonsillectomy. Therefore, this study was conducted to compare the effect of ketamine to propofol in reducing coughing at emergence from anesthesia in children who underwent tonsillectomy.

\section{Materials And Methods}

This parallel, double-blind, randomized clinical trial was conducted in a tertiary hospital of Shiraz University of Medical Sciences. After receiving approval from the ethics committee of Shiraz University of Medical Sciences, the trial was registered at the Islamic Republic of Iran Clinical Trials (IRCT) registry 
(registration number 2016101411662N11). Overall, 90 children aged 3-12 years in the ASA (American Society of Anesthesiologists) class I or II who were scheduled to undergo elective tonsillectomy under general anesthesia (G/A) were enrolled in this study. Children with a history of obstructive sleep apnea syndrome, bronchial asthma, allergic disorders, and upper respiratory tract infection symptoms prior to surgery were excluded from the study. Furthermore, those who use angiotensin-converting enzyme (ACE) inhibitors, developmental mental disorders, airway or facial abnormalities, and in whom the anesthesiologist tried more than once for endotracheal intubation were excluded from the study. The study protocol was explained to parents of the eligible children, and written informed consent was obtained from parents. The eligible children were randomly assigned into two groups (A and B) through simple randomization using computer-generated random numbers. Children in group A received propofol and those in group B received ketamine, at the end of anesthesia. This randomization was performed by a nurse anesthetist who had no role in administering the study.

In the operating room, routine monitoring for each child included oxygen saturation ( $\mathrm{SpO} 2)$, electrocardiogram, noninvasive blood pressure, and end-tidal carbon dioxide $\left(\mathrm{EtCO}_{2}\right)$. Induction of anesthesia was similar in both groups, including midazolam ( $0.03 \mathrm{mg} / \mathrm{kg}$ ), fentanyl (2 $\mu \mathrm{g} / \mathrm{kg})$, thiopental (5 $\mathrm{mg} / \mathrm{kg})$, and atracurium $(0.6 \mathrm{mg} / \mathrm{kg})$. Tracheal intubation with a suitable size was performed by an expert anesthesiologist in a single attempt. Anesthesia was maintained with $1.2 \%$ isoflurane in $\mathrm{N}_{2} \mathrm{O} / \mathrm{O}_{2}(50 \% / 50 \%)$ using controlled ventilation to maintain $\mathrm{EtCO}_{2}$ between 35 and $40 \mathrm{mmHg}$. At the end of the operation, isoflurane and $\mathrm{N}_{2} \mathrm{O}$ were discontinued and $100 \%$ oxygen was administered, and when the children's breathing returned to the spontaneous pattern, the residual neuromuscular block was reversed by neostigmine $(0.04 \mathrm{mg} / \mathrm{kg})$ plus atropine $(0.015 \mathrm{mg} / \mathrm{kg})$. After regular spontaneous breathing, children in groups A and B intravenously received $0.5-\mathrm{mg} / \mathrm{kg}$ propofol (Provive 1\%, Claris Lifesciences Ltd., Ahmedabad, Gujarat, India) and $0.5-\mathrm{mg} / \mathrm{kg}$ ketamine, respectively (Rotexmedica, Trittau, Germany). The dose of propofol and ketamine were selected according to Ozturk et al [13]. The ETT was removed after spontaneous breathing with an adequate tidal volume, and EtCO2 was achieved. After extubation, the children were transferred to the post-anesthesia care unit (PACU), given 5-6 L/minute of humidified oxygen through a facemask, and monitored for $\mathrm{SpO}_{2}$ and heart rate.

The primary outcome of this study was the incidence of cough at emergence, which was evaluated by cough scores. Cough scores were recorded based on the number of coughs: 0 (no coughing), 1 (minimal: once or twice), 2 (moderate: three to four times), or 3 (severe: five or more times). The scores were recorded when the children were extubated (time 0 ), every five minutes thereafter, and until 30 minutes after operation.

The secondary outcomes of this study were postoperative pain, sedation, and nausea and vomiting. Postoperative pain was measured by the Pain Faces Scale - Revised (Figure 1) in PACU every 10 minutes until 30 minutes and then at $1,2,4,8$, and 12 hours postoperation. Children with a score of $6 / 10$ or higher were considered having moderate-to-severe pain and were treated with $0.2 \mathrm{mg} / \mathrm{kg}$ of intravenous meperidine.

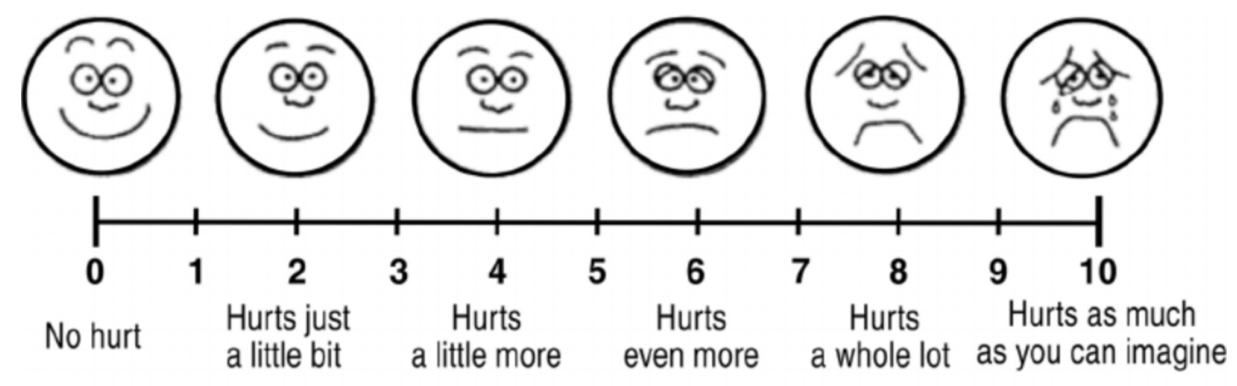

FIGURE 1: Pain Faces Scale - Revised

Postoperative sedation score was recorded according to the Ramsay Sedation Score $(0=$ restless, $1=$ calm, $2=$ sleepy, 3 = drowsy with response to verbal stimuli, 4 = drowsy without response to verbal stimuli, and $5=$ deep without response to painful stimuli) [14]. Postoperative nausea and vomiting were recorded as $0=$ no nausea or vomiting, 1 = nausea only, and 2 = retching and/or vomiting.

Children were evaluated during the study by a researcher who was not aware of patient group allocation.

\section{Statistical analysis}

According to previous studies, the primary endpoint of the study was the incidence of cough at emergence from anesthesia $[12,13]$. Therefore, for a $20 \%$ difference in the incidence of cough at emergence between the two groups and with a power of $80 \%$ and $\alpha$-error being set at 0.05 , at least 45 patients were required in each group. Initially, the Kolmogorov-Smirnov test was used to detect the normal distribution of the variables. 


\section{Cureus}

Then, mean and standard deviation (SD) were evaluated for numerical variables and frequency with percentage for categorical variables. For analysis of parametric data, independent t-tests and one-way ANOVA (analysis of variance) were used, and for comparison of nonparametric data, $\chi^{2}$ tests were used. All statistical analyses were performed using SPSS Version 18 (SPSS Inc., Chicago, IL, USA). All data are presented as means \pm SD and percentage, and a p-value of $<0.05$ was considered statistically significant.

\section{Results}

Among the 100 children who were scheduled to undergo tonsillectomy from August 2017 to October 2017, 5 were excluded because of acute respiratory tract infection, 3 due to a history of bronchial asthma, and 2 due to parental refusal. Therefore, in total 90 children were enrolled for the study and randomly allocated to groups A and B (Figure 2).

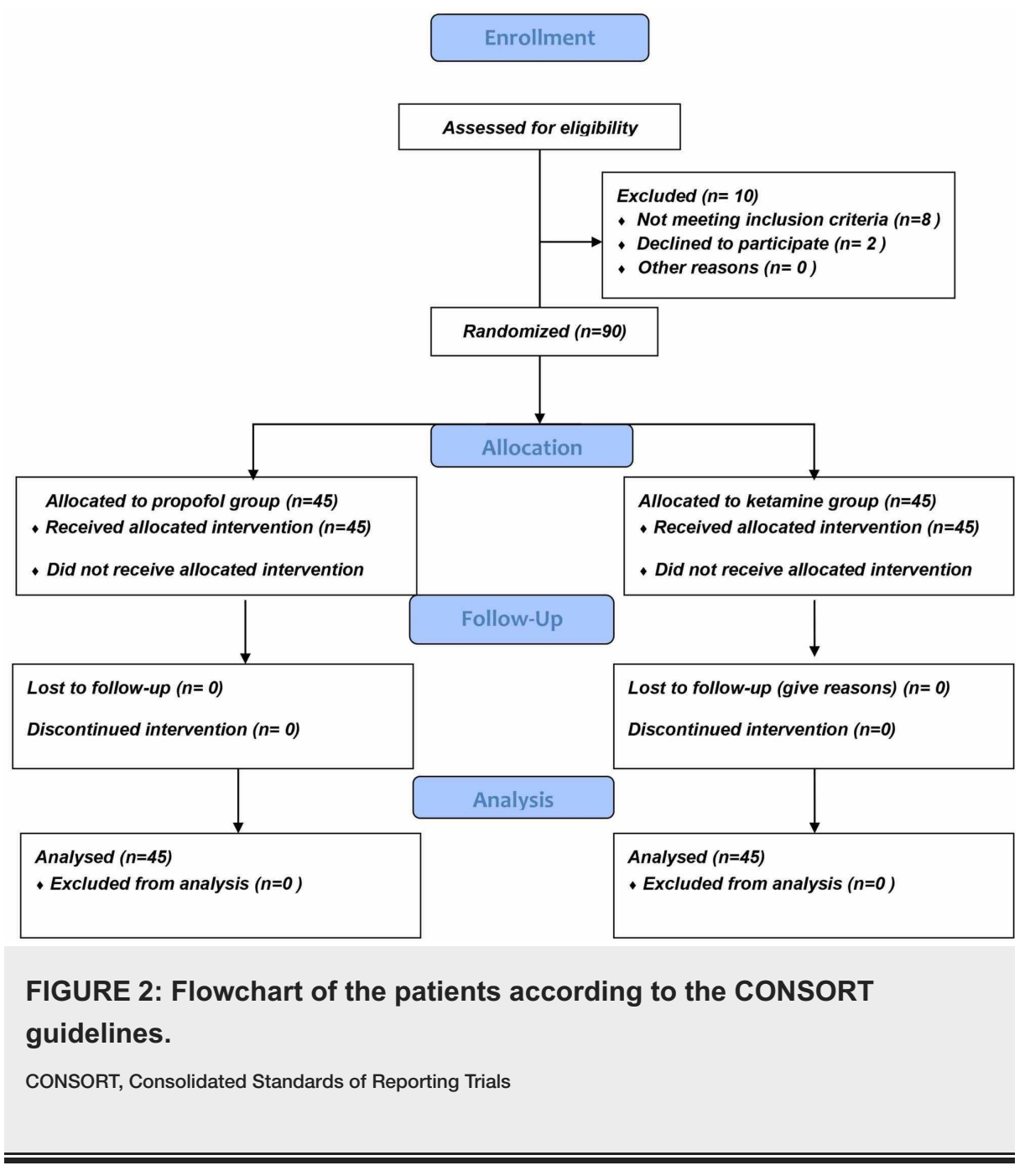

There were no significant differences in the demographic data, duration of anesthesia, time to extubation, and total fluid received by each participant $(\mathrm{P}>0.05$; Table 1$)$. 


\section{Cureus}

\begin{tabular}{|c|c|c|c|}
\hline & Propofol group $(n=45)$ & Ketamine group $(n=45)$ & P-value \\
\hline Age (years) & $6.64 \pm 2.54$ & $6.17 \pm 2.07$ & 0.333 \\
\hline Weight (kg) & $23.96 \pm 9.99$ & $22.66 \pm 6.86$ & 0.471 \\
\hline Height $(\mathrm{cm})$ & $110.42 \pm 15.74$ & $104.62 \pm 20.18$ & 0.130 \\
\hline Gender (male/female) & $29 / 16$ & $30 / 15$ & 1.133 \\
\hline Duration of anesthesia (minutes) & $41.08 \pm 2.99$ & $40.64 \pm 2.75$ & 0.460 \\
\hline Time to extubation (minutes) & $5.7 \pm 3.02$ & $7.2 \pm 0.43$ & 0.510 \\
\hline Fluid replacement (mL) & $304.11 \pm 115.02$ & $300.22 \pm 81.11$ & 0.850 \\
\hline
\end{tabular}

TABLE 1: Patients demographic data, anesthesia time, extubation time and fluid therapy between the two groups

Data are expressed as mean \pm standard deviation or as number (proportion).

The incidence of no cough at emergence from anesthesia was $82.2 \%$ in the propofol group and $15.5 \%$ in the ketamine group $(\mathrm{P}=0.00)$.The number of children who developed mild-to-moderate cough upon emergence and during 30 minutes after that is shown in Table 2. No participant developed severe cough on emergence from anesthesia and 30 minutes after that in both groups (Table 2).

\begin{tabular}{|c|c|c|c|c|c|c|c|c|c|}
\hline \multirow[b]{2}{*}{ Time } & \multicolumn{4}{|c|}{ Propofol group $(n=45)$} & \multicolumn{4}{|c|}{ Ketamine group $(n=45)$} & \multirow[b]{2}{*}{$\begin{array}{l}P \text { - } \\
\text { value }\end{array}$} \\
\hline & $\begin{array}{l}\text { No } \\
\text { cough }\end{array}$ & $\begin{array}{l}\text { Minimal } \\
\text { cough }\end{array}$ & $\begin{array}{l}\text { Moderate } \\
\text { cough }\end{array}$ & $\begin{array}{l}\text { Severe } \\
\text { cough }\end{array}$ & $\begin{array}{l}\text { No } \\
\text { cough }\end{array}$ & $\begin{array}{l}\text { Minimal } \\
\text { cough }\end{array}$ & $\begin{array}{l}\text { Moderate } \\
\text { cough }\end{array}$ & $\begin{array}{l}\text { Severe } \\
\text { cough }\end{array}$ & \\
\hline $\begin{array}{l}0 \\
\text { minutes }\end{array}$ & 37 & 8 & 0 & 0 & 7 & 24 & 14 & 0 & 0.000 \\
\hline $\begin{array}{l}5 \\
\text { minutes }\end{array}$ & 44 & 1 & 0 & 0 & 10 & 19 & 16 & 0 & 0.001 \\
\hline $\begin{array}{l}10 \\
\text { minutes }\end{array}$ & 42 & 3 & 0 & 0 & 15 & 20 & 10 & 0 & 0.009 \\
\hline $\begin{array}{l}15 \\
\text { minutes }\end{array}$ & 43 & 2 & 0 & 0 & 18 & 21 & 6 & 0 & 0.001 \\
\hline $\begin{array}{l}20 \\
\text { minutes }\end{array}$ & 36 & 9 & 0 & 0 & 20 & 15 & 10 & 0 & 0.003 \\
\hline $\begin{array}{l}30 \\
\text { minutes }\end{array}$ & 38 & 7 & 0 & 0 & 18 & 19 & 8 & 0 & 0.002 \\
\hline
\end{tabular}

TABLE 2: Number of patients who developed cough at emergence and 30 minutes after that in both groups

Children in the ketamine group had lower postoperative pain score than those in the propofol group until two hours postoperation ( $\mathrm{P}=0.001$; Table 3$)$; after that, there were no significant differences in pain scores of both groups due to pain rescue drug $(\mathrm{P}>0.05$; Table 3$)$. 


\section{Cureus}

\begin{tabular}{|c|c|c|c|}
\hline Time & Ketamine group $(n=45)$ & Propofol group ( $n=45)$ & P-value \\
\hline 10 minutes & $1.88 \pm 0.44$ & $8.26 \pm 0.49$ & 0.008 \\
\hline 20 minutes & $2.22 \pm 0.59$ & $6.64 \pm 1.88$ & 0.005 \\
\hline 30 minutes & $2.73 \pm 0.98$ & $4.24 \pm 0.77$ & 0.007 \\
\hline 60 minutes & $2.33 \pm 0.52$ & $4.62 \pm 2.83$ & 0.001 \\
\hline 2 hours & $1.08 \pm 1.44$ & $2.91 \pm 0.92$ & 0.58 \\
\hline 4 hours & $0.08 \pm 0.44$ & $0.24 \pm 0.44$ & 0.515 \\
\hline 8 hours & $0.00 \pm 00$ & $0.00 \pm 00$ & 0.517 \\
\hline 12 hours & $0.00 \pm 00$ & $0.00 \pm 00$ & 0.22 \\
\hline
\end{tabular}

TABLE 3: Postoperative pain score among children in the two groups according to the Pain Faces Scale - Revised

Furthermore, children in the propofol group were more calm and less drowsy than those in the ketamine group ( $\mathrm{P}<0.05$; Table 4$)$.

\begin{tabular}{|c|c|c|c|}
\hline Sedation score & Ketamine group $(n=45)$ & Propofol group $(n=45)$ & P-value \\
\hline Restless & $1(2.22 \%)$ & $5(11.11 \%)$ & 0.01 \\
\hline Calm & $15(33.33 \%)$ & $35(77.77 \%)$ & 0.001 \\
\hline Sleepy & $8(17.77 \%)$ & $4(8.88 \%)$ & 0.01 \\
\hline Drowsy with response to verbal stimuli & $16(35.55 \%)$ & $1(2.22 \%)$ & 0.001 \\
\hline Drowsy without response to verbal stimuli & $5(11.11 \%)$ & $0(0.00 \%)$ & 0.01 \\
\hline Deep without response to painful stimuli & $0(0.00 \%)$ & $0(0.00 \%)$ & 0.98 \\
\hline
\end{tabular}

TABLE 4: Postoperative agitation scores of children in both groups

Significant differences were also observed in the incidences of nausea and vomiting between the two groups during six hours postoperation ( $\mathrm{P}=0.002$; Figure 3 ).

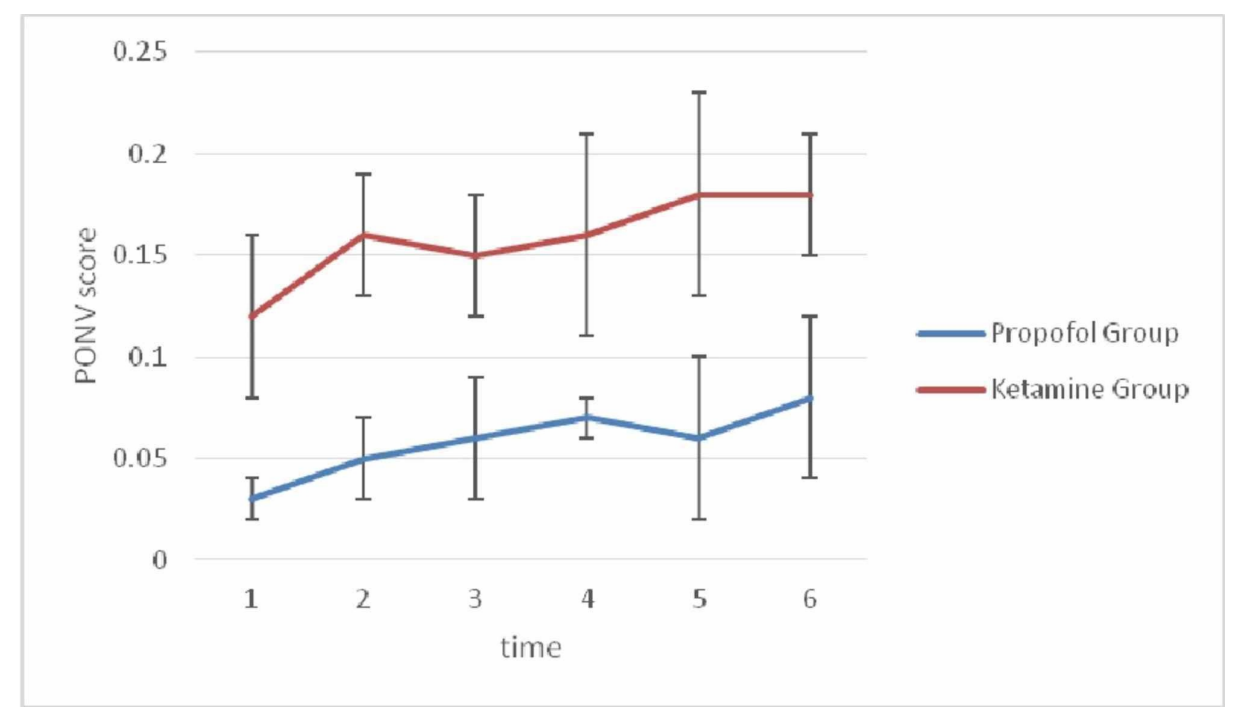


FIGURE 3: PONV in both groups during six hours postoperation.

PONV, postoperative nausea and vomiting

\section{Discussion}

This randomized clinical trial showed that a low dose of propofol $(0.5 \mathrm{mg} / \mathrm{kg})$ compared with a low dose of ketamine was more effective in reducing cough at emergence from isoflurane/N2O anesthesia in children who underwent tonsillectomy.

Coughing and their afferent fibers in the vagus nerve at emergence from anesthesia is a reflex that is due to chemical or mechanical stimulation of tissue nerve ending [15]. Also, cough reflex may be induced by other nerves and organs such as the trachea, diaphragm, and abdominal muscle [16]. Stimulation of N-methyl-Daspartate (NMDA) receptors in the trachea causes coughing response by ascending pathway from the trachea. Therefore, NMDA receptors play a key role in coughing response [17].

Previous studies have shown that ketamine effectively suppresses NMDA receptors, relaxes the smooth muscle of bronchus, and prevents bronchoconstriction [1]. Therefore, ketamine has been used as a bronchodilator by anesthesiologists [18]. Recently, ketamine has been shown to reduce laryngospasm, but not coughing, at emergence from anesthesia [12]. In this study, we also found ketamine to be not as effective as propofol in reducing the incidence of cough at emergence from anesthesia.

A study by Jung et al. showed that propofol could reduce cough response at emergence from anesthesia [19]. Another study by Orser et al. reported that propofol could effectively inhibit NMDA receptors. Therefore, propofol could diminish cough reflex due to airway irritation by blocking the NMDA receptors in the trachea and blocking the ascending pathway from the trachea [20]. Although ketamine is an NMDA receptor blocker, Pak et al. showed that low-dose ketamine could not diminish cough response upon emergence from anesthesia in children, possibly because ketamine increases bronchotracheal secretion that induces cough response, hence resulting in the negative effect of ketamine on the cough upon emergence from anesthesia [12].

Our results were similar to those by Pak et al., and propofol was found more effective than ketamine in reducing cough response upon emergence from anesthesia [12]. However, we used isoflurane, which is more irritating to the airway than sevoflurane, which was used by Pak et al. Furthermore, all the children in our study underwent tonsillectomy, which is considered an invasive throat surgery that raises the risk of cough response. However, the study by Pak et al. included children who underwent herniorraphy, and the upper airway was not manipulated. Therefore, our study has stronger evidence to support the antitussive effect of low-dose propofol in children.

Another study by Ozturk et al. reported that neither propofol nor ketamine was effective in decreasing the incidence of cough at emergence from anesthesia and in the postanesthesia recovery time [13]. However, they used remifentanil during anesthesia for bronchoscopy. Although opioids have a central antitussive effect, potent and short-acting opioids such as remifentanil could induce cough response through activation of the vagus nerve, and bronchoconstrictive effect. Therefore, the study did not conclude that propofol has an antitussive effect.

Similar to previous studies, our study also observed that children in the propofol group had a lower incidence of postoperative nausea and vomiting. Also, children in the propofol group had lower sedation scores and less agitation than those in the ketamine group. Children who received ketamine were more sedated in PACU, as reported previously, although we used a low dose of ketamine [12].

This study has some limitations. First, we should have another group of children as a control group. Second, in future studies, it is better to compare different doses of propofol $(0.25 \mathrm{mg} / \mathrm{Kg}, 0.5 \mathrm{mg} / \mathrm{Kg})$ to the find best dosage of propofol or try a mixture of low-dose ketamine and propofol (ketofol) to find the best drug mixture to decrease postoperative pain and suppress cough reflex following tonsillectomy.

\section{Conclusions}

In conclusion, for the children who underwent tonsillectomy at the end of $\mathrm{G} / \mathrm{A}$, low-dose propofol at 0.5 $\mathrm{mg} / \mathrm{kg}$ is more effective than low-dose ketamine in reducing cough at emergence from anesthesia, with a lower incidence of nausea and vomiting. Also, low-dose propofol results in a lower sedation score in children.

\section{Additional Information}

\section{Disclosures}


Human subjects: Consent was obtained by all participants in this study. Shiraz Medical School Research Ethic Committee issued approval IR.sums.med.rec.1396.52. Animal subjects: All authors have confirmed that this study did not involve animal subjects or tissue. Conflicts of interest: In compliance with the ICMJE uniform disclosure form, all authors declare the following: Payment/services info: All authors have declared that no financial support was received from any organization for the submitted work. Financial relationships: All authors have declared that they have no financial relationships at present or within the previous three years with any organizations that might have an interest in the submitted work. Other relationships: All authors have declared that there are no other relationships or activities that could appear to have influenced the submitted work.

\section{References}

1. Conceicao MJ, Bruggemann DA, Conceicao DC, Carneiro Leao C: Effect of an intravenous single dose of ketamine on postoperative pain in tonsillectomy patients. Paediatr Anaesth. 2006, 16:962-7. 10.1111/j.1460-9592.2006.01893.x

2. Lee B, Lee JR, Na S: Targeting smooth emergence: the effect site concentration of remifentanil for preventing cough during emergence during propofol-remifentanil anaesthesia for thyroid surgery. $\mathrm{Br} \mathrm{J}$ Anaesth. 2009, 102:775-8. 10.1093/bja/aep090

3. Kim ES, Bishop MJ: Cough during emergence from isoflurane anesthesia . Anesth Analg. 1998, 87:1170-4. 10.1097/00000539-199811000-00036

4. Afshan G, Chohan U, Qamar-Ul-Hoda M, Kamal RS: Is there a role of a small dose of propofol in the treatment of laryngeal spasm?. Paediatr Anaesth. 2002, 12:625-8. 10.1046/j.1460-9592.2002.00937.x

5. Hamilton ND, Hegarty M, Calder A, Erb TO, von Ungern-Sternberg BS: Does topical lidocaine before tracheal intubation attenuate airway responses in children? An observational audit. Pediatr Anaesth. 2012, 22:34550. 10.1111/j.1460-9592.2011.03772.x

6. Minogue SC, Ralph J, Lampa MJ: Laryngotracheal topicalization with lidocaine before intubation decreases the incidence of coughing on emergence from general anesthesia. Anesth Analg. 2004, 99:1253. 10.1213/01.ANE.0000132779.27085.52

7. Neelakanta G, Miller J: Minimum alveolar concentration of isoflurane for tracheal extubation in deeply anesthetized children. Anesthesiology. 1994, 80:811-3. 10.1097/00000542-199404000-00013

8. Venkatesan T, Korula G: A comparative study between the effects of $4 \%$ endotracheal tube cuff lignocaine and $1.5 \mathrm{mg} / \mathrm{kg}$ intravenous lignocaine on coughing and hemodynamics during extubation in neurosurgical patients: a randomized controlled double-blind trial. J Neurosurg Anesthesiol. 2006, 18:230-4. 10.1097/00008506-200610000-00002

9. Guler G, Akin A, Tosun Z, Eskitascoglu E, Mizrak A, Boyaci A: Single-dose dexmedetomidine attenuates airway and circulatory reflexes during extubation. Acta Anaesthesiol Scand. 2005, 49:1088-91. 10.1111/j.1399-6576.2005.00780.x

10. Rajan S, Malayil GJ, Varghese R, Kumar L: Comparison of usefulness of ketamine and magnesium sulfate nebulizations for attenuating postoperative sore throat, hoarseness of. voice, and cough. Anesth Essays Res. 2017, 11:287-93. 10.4103/0259-1162.181427

11. Yeh CC, Wu CT, Huh BK, Lee MS, Lin SL, J Sheen M, Wong CS: Premedication with intravenous low-dose ketamine suppresses fentanyl-induced cough. J Clin Anesth. 2007, 19:53-6. 10.1016/j.jclinane.2006.05.021

12. Pak HJ, Lee WH, Ji SM, Choi YH: Effect of a small dose of propofol or ketamine to prevent coughing and laryngospasm in children awakening from general anesthesia. Korean J Anesthesiol. 2011, 60:25-9. 10.4097/kjae.2011.60.1.25

13. Ozturk T, Acıkel A, Yılmaz O, Topçu I, Çevıkkalp E, Yuksel H: Effects of low dose propofol vs ketamine on emergence cough in children undergoing flexible bronchoscopy with sevoflurane-remifentanil anesthesia: a randomized, double-blind, placebo-controlled trial. J Clin Anesth. 2016, 35:90-5. 10.1016/j.jclinane.2016.06.025

14. Wu X, Shan C, Peng B, Shi X, Zhang F, Cao J: Comparison of desflurane and sevoflurane on postoperative recovery quality after tonsillectomy and adenoidectomy in children. Exp Ther Med. 2019, 17:4561-7. 10.3892/etm.2019.7467

15. Canning BJ: Anatomy and neurophysiology of the cough reflex: ACCP evidence-based clinical practice guidelines. Chest. 2006, 129:33-47. 10.1378/chest.129.1_suppl.33S

16. Wilddicombe JG: Afferent receptors in the airways and cough . Respir Physiol. 1998, 114:5-15. 10.1016/s0034-5687(98)00076-0

17. Sant'Ambrogio G: Afferent pathways for the cough reflex. Bull Eur Physiopathol Respir. 1987, 23:19-23.

18. Burburan SM, Xisto DG, Rocco PR: Anaesthetic management in asthma. Minerva Anestesiol. 2007, 73:35765.

19. Jung SY, Park HB, Kim JD: The effect of a subhypnotic dose of propofol for the prevention of coughing in adults during emergence from anesthesia with sevoflurane and remifentanil. Korean J Anesthesiol. 2014, 66:120-6. 10.4097/kjae.2014.66.2.120

20. Orser BA, Bertlik M, Wang LY, MacDonald JF: Inhibition by propofol (2,6 di-isopropylphenol) of the Nmethyl-D-aspartate subtype of glutamate receptor in cultured hippocampal neurones. Br J Pharmacol. 1995, 116:1761-8. 10.1111/j.1476-5381.1995.tb16660.x 